\title{
Subjective health status and health-related quality of life among women with Recurrent Vulvovaginal Candidosis (RVVC) in Europe and the USA
}

Samuel Aballéa ${ }^{1 *+}$, Florent Guelfucci ${ }^{2^{*+}}$, Julian Wagner ${ }^{3}$, Amine Khemiri ${ }^{4}$, Jean-Paul Dietz ${ }^{5}$, Jack Sobel ${ }^{6}$ and Mondher Toumi ${ }^{1 *}$

\begin{abstract}
Background: Recurrent vulvovaginal candidosis (RWC) is a chronic condition causing discomfort and pain. Health status and health-related quality of life (HRQOL) in RWC were never previously described using validated questionnaires. The objective of this study is to describe subjective health status and HRQoL and estimate health state utilities among women with RWC.

Methods: A cross-sectional online survey was conducted among women who reported having suffered four or more yeast infections over the past 12 months, in five European countries (France, Germany, Italy, Spain and the UK) and the USA. Index scores were derived from the EQ-5D, a questionnaire providing a single index value for health status. The SF-36 questionnaire was used for HRQoL assessment. Information on disease severity, treatment patterns and productivity was also collected.

Results: 12,834 members of online research panels were contacted. Among them, 620 women with RWC (5\%) were selected to complete the full questionnaire. The mean EQ-5D index score was 0.70 (95\% confidence interval: $[0.67,0.72])$ and the difference between women with a yeast infection at the time of questionnaire completion and other respondents was $0.05(p=0.47)$. The EQ-5D index score increased significantly with the time since last infection $(p<0.001)$. $68 \%$ of women reported depression/anxiety problems during acute episode, and $54 \%$ outside episodes, compared to less than $20 \%$ in general population ( $p<0.001)$. All SF-36 domain scores were significantly below general population norms. Mental health domains were the most affected. The impact on productivity was estimated at 33 lost work hours per year on average, corresponding to estimated costs between $€ 266 /$ year and $€ 1,130 /$ year depending on the country.

Conclusions: Subjective health status and HRQoL during and in between acute inflammatory episodes in women with RWC are significantly worse than in the general population, despite the use of antifungal therapy. The average index score in women with RWC is comparable to other diseases such as asthma or COPD and worse than diseases such as headache/migraine according to US and UK catalogs of index scores. The survey also revealed a significant loss of productivity associated with RWC.
\end{abstract}

\footnotetext{
* Correspondence: saballea@gmail.com; florent_guelfucci@yahoo.fr; mondher.toumi@univ-lyon1.fr

${ }^{\dagger}$ Equal contributors

${ }^{1}$ Université Lyon I, decision sciences and health policies, Lyon, France

Full list of author information is available at the end of the article
} 


\section{Background}

Recurrent vulvovaginal candidosis (RVVC) is a debilitating chronic infectious condition. It is defined as four or more acute inflammatory episodes of VulvoVaginal Candidosis (VVC), also known as vaginal yeast infection, within a year $[1,2]$. The prevalence of RVVC is estimated at $6-8 \%$ in women aged between 18 and 65 years in the USA and Western Europe, according to two large studies $[3,4]$ and similar estimates can be derived from assessments of RVVC prevalence as proportion of VVC cases and studies on population-based VVC prevalence [3-8].

The main symptoms of yeast infections are inflammation, itching, an abnormal vaginal discharge and painful sexual intercourse and urination. Such symptoms cause variable but often severe discomfort and pain. Acute inflammatory episodes usually are treated with anti-fungal drugs of the azole class. They are efficient in clearing the acute infection, but are unable to prevent recurrences, which occur on average after a few months only. Guidelines from a number of medical associations recommend a long-term suppressive treatment regimen with an antifungal drug, usually fluconazole, for at least 6 months, off label $[9,10]$, which can prevent recurrences for the duration of the therapy, whereas recurrence rates of $60-70 \%$ within 6 months after treatment cessation were reported $[11,12]$. A modified weaning scheme over 12-18 months achieved a lower recurrence rate (36\%) within 6 months after complete treatment cessation [13]. The cost of longterm treatment has been estimated at AUD 900 (\$ 862) in Australia [14]. Many RVVC patients turn to alternative remedies like yoghurt and vinegar which only have very short-term palliative effects $[15,16]$.

Clinical impression is that RVVC patients, despite current treatment options, suffer from a substantially impaired health-related quality of life (HRQoL), but quantifiable evidence is scarce. Nyirjesy et al. applied several validated pain, stress and depression measurements to a population of physician-diagnosed patients $(\mathrm{N}=38)$ and observed a proportion of $29 \%$ with a clinical depression [17]. Mendling et al. reported SF-36 scores and further HRQoL-related information from a longitudinal study on RVVC patients receiving different therapeutic treatments $(\mathrm{N}=3 \times 30)$, indicating that mental health was more affected than physical health [18].

To our knowledge, no other study has been conducted to elicit subjective health status or to assess global HRQoL of RVVC patients. In times of limited health care budgets, the availability of quantitative data on the medical need of a debilitating but not life-threatening condition, comparable across countries and indications, are a prerequisite for stakeholders and decision makers to engage into research and development of innovative treatment approaches.

The primary objective of this study was to assess subjective health status and HRQoL, and more specifically to estimate health state utilities, among women with RVVC, compared to general female population. Secondary objectives were to describe the impact of the disease on subjective health status during and in between acute inflammatory episodes, and to assess productivity and activity impairment.

\section{Methods}

\section{Respondent recruitment and selection}

A cross-sectional online survey was conducted in five European countries (France, Germany, Italy, Spain and UK) and USA using pre-existing market research panels. A target sample size of 100 respondents with RVVC was set for each country. Respondents were recruited using the Research Now family of panels which included $6,000,000$ panellists [19]. The panellists received an incentive from $€ 0.5$ to $€ 5$ for their participation in the survey.

The questionnaire was initially developed and launched in the UK. It was first tested on 40 persons from the UK panel (soft launch). The purpose of this pilot phase was to check whether there was any obvious misunderstanding of questions or unexpected answers, and that the routing between questions was correct. Based on findings from the pilot study, minor corrections were made (described below), and other panel members from the UK were invited to participate in the survey until 100 full questionnaires were completed (full launch). After reviewing the collected data, the questionnaire was translated and launched in other countries. Any respondents with a time of completion lower than $33 \%$ of the RVVC sample median completion time were removed.

The questionnaire started with five screening questions to identify women with RVVC aged between 18 and 65 years who had been told at least once by a health care professional that they had a yeast infection, and who experienced at least four yeast infections over the past 12 months. Age quotas were used to ensure that the sample was representative of women with RVVC. The screening questions were slightly re-worded after the soft launch in the UK. It was initially asked UK participants if they had more than four episodes in the last 12 months, and the exact number of episodes was established later in the full questionnaire. Nine women had answered during the screening phase that they had more than four yeast infections in the last 12 months, but subsequently gave a number of infections lower than four in the main part of the questionnaire. We did not consider those women in our analysis and revised the questionnaire accordingly. In the final version, women were asked to state the exact number of episodes in the screening section, to determine their eligibility for completing the main questionnaire. The women who were identified with RVVC in the screening completed the main questionnaire immediately after answering the screening questions. 
The main questionnaire started with two questions to determine whether the participant had an acute VVC episode at the time of answering the questionnaire, and if not, the time elapsed since the last episode.

\section{Health status and HRQoL measurement}

As the primary objective was to compare subjective health status and HRQoL in women with RVVC to general population norms, generic instruments were used: the EQ-5D to elicit health state utilities [20] and the SF-36 to provide more detailed description of HRQoL [21,22]. EQ-5D is one of the most widely used preference-based instruments for the assessment of subjective health status enabling comparisons with other diseases, and helping payers to arbitrate on allocation of resources between different treatments, potentially in different therapeutic areas. This instrument is recommended by the UK National Institute for Health and Clinical Excellence (NICE) for eliciting utilities, i.e. weights used to estimate quality-adjusted lifeyears in the context of cost-effectiveness analysis [23]. EQ$5 \mathrm{D}$ is designed for self-completion by respondents and is suitable for use in postal or online surveys [24].

As it takes only a short time to complete, it was possible to ask the respondents to answer the EQ-5D twice. Firstly, respondents described their health state on the day of completing the questionnaire. Secondly, respondents who indicated having an acute episode on that day were asked to describe their health state on days without infection; others were asked to describe their health state on days with infection (Figure 1). Therefore, we were able to compare the health states during acute episode and between episodes for each woman in the last 12 months. However, these data were not used for the UK, because the question about having an episode at the time of completing the questionnaire appeared to be misunderstood. This question was rephrased before launching the study for other countries.

The SF-36 (version two) [21], another generic questionnaire, is more detailed than EQ-5D and frequently used to describe the disease's burden in terms of HRQoL compared to the general population. It consists of 36 items, from which eight domain scores and two summary measures of health (the Physical Health Component Summary, PCS, and the Mental Component Summary, MCS) can be derived [25]. Validated translations are available for both EQ-5D and SF-36 for all the countries included in the study.

\section{Disease characteristics and management}

To investigate the relationship between disease characteristics and HRQoL, another part of the questionnaire aimed to gather information on disease characteristics (frequency and duration of episodes, duration of disease) and disease management (history of long-term antifungal therapy, history of referral to a specialist).

\section{Work productivity and activity impairment}

Questions on the impact on work and activities were directly adapted from a validated questionnaire (WPAI) [26] replacing "During the past seven days ..." by "Thinking back to your most recent yeast infection..." and "...your health problems..." by "...your last infection...". In the absence of validation of the questionnaire in French, German or Italian, the questions have been translated by native speakers and validated by experts.

The cost associated with work hours lost due to RVVC was estimated by country, by multiplying the corresponding number of lost work hours by the average hourly wage. Average national hourly wages were obtained using average annual wages in 2011 and average annual hours actually worked per worker [27] provided by the Organisation for Economic Co-operation and Development (OECD).

\section{Utility valuation}

Utility scores were estimated during acute episodes and between acute episodes using EQ-5D, and were compared to general population scores from the literature.

Different value sets were available for EQ-5D, based on preference weights elicited in different countries [20]. In order to facilitate comparisons and generate an average score across all countries, preference weights elicited from the general population of the UK were first applied for all countries. The UK value set is the most widely used, and recommended by the EuroQol Group for use in costeffectiveness/utility studies and comparative studies and to facilitate international comparisons [20,28]. These weights were generated from a large sample of the general population in the UK using the time-trade off (TTO) technique [29]. Utilities were also estimated based on preference weights elicited locally, in France, Germany, Spain and the USA. This was not possible for Italy where no set of values was developed.

\section{Statistical analysis}

EQ-5D norms for proportions of patients reporting problems on each of the five EQ5D dimensions were reported by the EuroQol group [30] for the USA, Spain and Germany and by König et al. [29] for France and Italy. EQ-5D utility population norms were available for the US [31] and the UK [32,33], and calculated using proportions of patients by level on each dimension and country specific valuation formulas for other countries.

Utility values in general population were adjusted on the age distribution of the RVVC sample for Spain, Germany, US and UK but no age adjustments were made for France and Italy, as no breakdown by age group was found. However, König et al. analysed the effect of country on the occurrence of problems using multiple logistic regressions and controlling for socio-demographic variables. The paper presented odds ratio for different age categories. In 


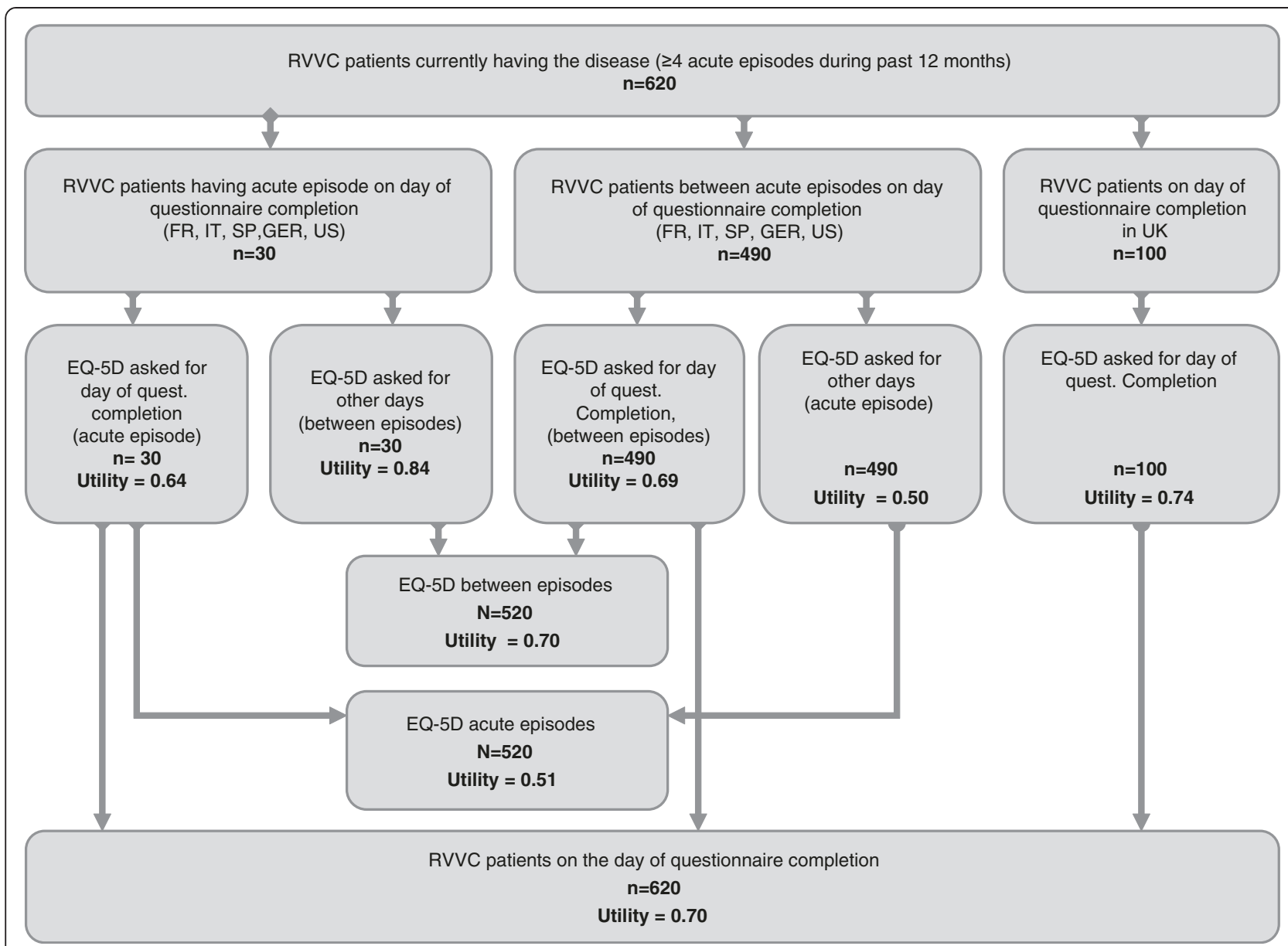

Figure 1 Mean EQ-5D utilities (based on UK TTO tariff) by patient subgroup, according to presence of symptoms on the day of questionnaire completion.

a sensitivity analysis, age-adjusted population norms were obtained by applying these odds ratios on all dimensions of the EQ-5D.

Proportions of women reporting problems on each EQ$5 \mathrm{D}$ dimension were compared with population norms using the chi-square test of independence or Fisher's exact test. Linear regression analyses on the EQ-5D utility at completion of the questionnaire were performed to determine the drivers of EQ-5D utility among disease-related variables, adjusting on patient characteristics.

For SF-36, individual scores can be compared with the population mean by transforming the individual score into standardized scores (Z-score and T-score) for each domain and summary component. As SF-36 norms were not found for most countries, the US population means and standard deviations were systematically used in the calculation of the standardized scores. After transformation, the average score in the general population was 50 and the standard deviation is 10 . Whenever a domain or summary score was below 50, this indicated that HRQoL was worse in the studied population compared to the general population, and each point was one-tenth of a standard deviation. The correlation between EQ-5D dimensions and the SF-36 scales were calculated using the Spearman correlation coefficients.

\section{Results}

\section{Patients \& disease characteristics}

12,834 members of online research panels were contacted and entered the self- screening questions. 865 women did not complete it and 4,389 women were not included in the study because the target number of respondents in their age group had been reached, not because they did not fulfil the criteria for RVVC. Of 7,580 (59\%) women who completed the screening questions (excluding women out of the quotas), 639 (8.4\%) were selected to complete the full questionnaire (5\% of total contacted). The full questionnaire was completed by 620 women. Their mean age was 32 years (Table 1 ).

Thirty women $(5.8 \%)$ reported suffering a yeast infection on the day of completing the questionnaire, across all countries (except UK) and 20.6\% had an infection less 


\section{Table 1 Patient characteristics}

\begin{tabular}{|c|c|c|c|c|c|c|c|c|}
\hline & & UK & France & Spain & Italy & Germany & USA & Total \\
\hline & N & 100 & 107 & 100 & 105 & 106 & 102 & 620 \\
\hline \multirow[t]{2}{*}{ Age } & Mean & $30.3(9.6)$ & $32.3(10.8)$ & $32.1(10.6)$ & $32.1(10.6)$ & $31.4(10.8)$ & $32.1(10.8)$ & $31.8(10.5)$ \\
\hline & Median (range) & 27.0 [18.0; 56.0] & $29.0[18.0 ; 61.0]$ & $29.0[18.0 ; 60.0]$ & $28.0[19.0 ; 60.0]$ & $28.0[18.0 ; 62.0]$ & $29.0[18.0 ; 63.0]$ & $28.0[18.0 ; 63.0]$ \\
\hline \multirow[t]{5}{*}{ Marital status } & Single & $37(37.0 \%)$ & $23(21.50 \%)$ & $23(21.7 \%)$ & $48(45.7 \%)$ & $37(35.6 \%)$ & 30 (29.4\%) & 195 (31.5\%) \\
\hline & Married & $22(22.0 \%)$ & $33(30.84 \%)$ & 35 (33.0\%) & $32(30.5 \%)$ & $32(30.8 \%)$ & 50 (49.0\%) & 204 (32.9\%) \\
\hline & Divorced & $2(2.0 \%)$ & $7(6.54 \%)$ & $3(2.8 \%)$ & $5(4.8 \%)$ & $1(1.0 \%)$ & $6(5.9 \%)$ & $23(3.7 \%)$ \\
\hline & Separated & $1(1.0 \%)$ & 0 & $2(1.9 \%)$ & 0 & $4(3.9 \%)$ & $3(2.9 \%)$ & $10(1.6 \%)$ \\
\hline & Living with partner & $38(38.0 \%)$ & $44(41.1 \%)$ & $43(40.6 \%)$ & $20(19.1 \%)$ & 30 (28.9\%) & $13(12.8 \%)$ & 188 (30.3\%) \\
\hline Number of employed women & $\mathrm{N}(\%)$ & $71(71.0 \%)$ & $83(77.5 \%)$ & $62(62.0 \%)$ & $60(57.1 \%)$ & 78 (73.5\%) & 69 (67.7\%) & $423(68.2 \%)$ \\
\hline
\end{tabular}


Table 2 Disease characteristics \& treatment

\begin{tabular}{|c|c|c|c|c|c|c|c|c|}
\hline & & $\mathrm{UK}^{*}$ & France & Spain & Italy & Germany & USA & Total \\
\hline $\begin{array}{l}\text { Last time the women } \\
\text { experienced the symptoms }\end{array}$ & $\mathrm{N}$ & & 107 & 100 & 105 & 106 & 102 & 520 \\
\hline Today & N (\%) & & $5(4.7 \%)$ & $4(4.0 \%)$ & $7(6.7 \%)$ & $7(6.6 \%)$ & $7(6.9 \%)$ & $30(5.8 \%)$ \\
\hline Less than a week ago & N (\%) & & $27(25.2 \%)$ & $18(18.0 \%)$ & $20(19.1 \%)$ & $20(18.9 \%)$ & $22(21.6 \%)$ & $107(20.6 \%)$ \\
\hline 1 to 4 weeks ago & N (\%) & & $42(39.3 \%)$ & 49 (49.0\%) & $55(52.4 \%)$ & $42(39.6 \%)$ & $47(46.1 \%)$ & $235(45.2 \%)$ \\
\hline 1 to 3 months ago & N (\%) & & $24(22.4 \%)$ & $24(24.0 \%)$ & $15(14.3 \%)$ & $23(21.7 \%)$ & $24(23.5 \%)$ & $110(21.2 \%)$ \\
\hline 3 to 6 months ago & N (\%) & & $6(5.6 \%)$ & $4(4.0 \%)$ & $5(4.8 \%)$ & $10(9.4 \%)$ & $2(2.0 \%)$ & $27(5.2 \%)$ \\
\hline More than 6 months ago & N (\%) & & $3(2.8 \%)$ & $1(1.0 \%)$ & $3(2.9 \%)$ & $4(3.8 \%)$ & 0 & $11(2.1 \%)$ \\
\hline Symptoms today: $\mathrm{n}(\%)$ & N & & 5 & 4 & 7 & 7 & 7 & 30 \\
\hline Vaginal itching and/or Burning & N (\%) & & $5(100.0 \%)$ & $4(100.0 \%)$ & $7(100.0 \%)$ & $6(85.7 \%)$ & $4(57.1 \%)$ & $26(86.7 \%)$ \\
\hline $\begin{array}{r}\text { Thick, white or yellowish } \\
\text { vaginal discharge }\end{array}$ & N (\%) & & $4(80.0 \%)$ & $4(100.0 \%)$ & $6(85.7 \%)$ & $4(57.1 \%)$ & $5(71.4 \%)$ & $23(76.7 \%)$ \\
\hline Pain on intercourse & N (\%) & & $2(40.0 \%)$ & $3(75.0 \%)$ & $2(28.6 \%)$ & $1(14.3 \%)$ & $3(42.9 \%)$ & $11(36.7 \%)$ \\
\hline Pain and burning on urination & N (\%) & & 0 & $1(25.0 \%)$ & $4(57.1 \%)$ & $3(42.9 \%)$ & $4(57.1 \%)$ & $12(40.0 \%)$ \\
\hline \multicolumn{9}{|l|}{ Number of infections } \\
\hline & $\mathrm{N}$ & 100 & 107 & 100 & 105 & 106 & 102 & 620 \\
\hline & Mean (SD) & $5.74(2.19)$ & $5.22(1.43)$ & $5.22(1.45)$ & $5.28(1.54)$ & $5.05(1.26)$ & $5.60(1.81)$ & $5.34(1.64)$ \\
\hline \multicolumn{9}{|l|}{ Duration of infection (days) } \\
\hline & N & 100 & 107 & 100 & 105 & 106 & 102 & 620 \\
\hline & Mean (SD) & $6.96(5.00)$ & $7.01(4.31)$ & $10.75(12.25)$ & $7.43(4.94)$ & $6.50(4.76)$ & $6.66(4.65)$ & $7.57(6.77)$ \\
\hline $\begin{array}{l}\text { Patients treatment with } \\
\text { long-term antifungal therapy }\end{array}$ & N & 100 & 107 & 100 & 105 & 106 & 102 & 620 \\
\hline Patients never treated & N (\%) & 68 (68.00\%) & $45(42.06 \%)$ & $45(42.45 \%)$ & $29(27.62 \%)$ & 72 (69.23\%) & $64(62.75 \%)$ & $321(51.8 \%)$ \\
\hline Patients currently treated & N (\%) & $12(12.00 \%)$ & $29(27.10 \%)$ & $25(23.81 \%)$ & $42(40.38 \%)$ & $9(8.49 \%)$ & $26(25.49 \%)$ & $141(22.7 \%)$ \\
\hline Previously treated & N (\%) & $20(20.00 \%)$ & $33(30.84 \%)$ & $36(33.96 \%)$ & $34(32.38 \%)$ & $23(22.11 \%)$ & $12(15.79 \%)$ & $158(25.5 \%)$ \\
\hline
\end{tabular}

*Data about symptoms not available for the UK, as questions about symptoms were formulated differently in the UK version.

than a week ago. The mean duration of an acute episode was relatively homogeneous between countries, varying from 6.5 days to 7.4 days, apart from Spain (10.8 days). The average number of infections in the last 12 months was between five and six (Table 2). Overall, the periods with infection added up to 5.8 weeks on average over 12 months.

$48 \%$ of the RVVC women $(\mathrm{N}=299)$ had been treated with a long-term antifungal treatment at least once (Table 2). Among them, 141 were treated at the time they answered the questionnaire, and 158 were treated previously. Among the 158 women previously treated with long-term antifungal, 121 (77\%) completed the normal course of the treatment and $92(61 \%)$ had at least one relapse since stopping long-term antifungal treatment. $75 \%$ of the women reported they had seen a gynaecologist.

Impact of RVVC on subjective health status and HRQoL The proportion of women with problems related to pain/discomfort of EQ-5D was $63 \%$ on average (from
$55 \%$ in Germany to $78 \%$ in Italy) whereas the proportions in the general population did not exceed 35\% (from 23\% in Spain to 35\% in France). Anxiety/depression was also significantly affected, with $53 \%$ of women reporting some or severe problems on that dimension (from $43 \%$ in UK to $62 \%$ in Italy), compared to below $20 \%$ in the general population. Substantial differences between our sample and the general population were also found for problems related to usual activities. Differences vs. the general population were significant for all dimensions (see Table 3).

The average utility score for women with RVVC across six countries was estimated at 0.70 on the day of completion of the questionnaire (Table 4). The utilities obtained using the country-specific preference weights were significantly lower than the age-adjusted general population, with a difference vs. general population norms ranging from 0.08 in Germany to 0.21 in Spain (Table 4).

All SF-36 domain scores, presented in the Figure 2, were significantly lower among women with RVVC than 
Table 3 Proportions by EQ-5D dimensions and correlation with SF-36

\begin{tabular}{|c|c|c|c|c|c|c|c|c|}
\hline & & $\begin{array}{r}\text { Number of } \\
\text { women }\end{array}$ & $\begin{array}{r}\text { EQ-5D } \\
\text { mobility }\end{array}$ & $\begin{array}{r}\text { EQ-5D } \\
\text { self-care }\end{array}$ & $\begin{array}{r}\text { EQ-5D usual } \\
\text { activities }\end{array}$ & $\begin{array}{r}\text { EQ-5D pain/ } \\
\text { discomfort }\end{array}$ & $\begin{array}{r}\text { EQ-5D anxiety/ } \\
\text { depression }\end{array}$ & Source \\
\hline \multicolumn{9}{|c|}{ Proportions of patients with problems at the completion day } \\
\hline \multirow[t]{3}{*}{ UK } & RWC sample & $N=100$ & $17.0 \%$ & $8.0 \%$ & $24.0 \%$ & $60.0 \%$ & $43.0 \%$ & \\
\hline & General population & $N=1926$ & $13.4 \%$ & $3.1 \%$ & $11.9 \%$ & $25.4 \%$ & $18.4 \%$ & eurogol \\
\hline & Test (p-value) & & $P<0.0001$ & $P<0.0001$ & $P<0.0001$ & $P<0.0001$ & $P<0.0001$ & \\
\hline \multirow[t]{4}{*}{ France } & RWC sample & $N=107$ & $12.2 \%$ & $5.6 \%$ & $17.8 \%$ & $65.4 \%$ & $57.0 \%$ & \\
\hline & General population & $N=2,892$ & $13.2 \%$ & $4.1 \%$ & $10.0 \%$ & $35.3 \%$ & $14.6 \%$ & Konig et al. \\
\hline & General pop (adjusted) & $N=2,892$ & $17.1 \%$ & $5.4 \%$ & $13.5 \%$ & $49.0 \%$ & $21.8 \%$ & \\
\hline & Test (p-value) & & $P<0.0001$ & $P<0.0001$ & $P<0.0001$ & $P<0.0001$ & $P<0.0001$ & \\
\hline \multirow[t]{3}{*}{ Spain } & RWC sample & $N=100$ & $20.0 \%$ & $20.0 \%$ & $29.0 \%$ & $60.0 \%$ & $49.0 \%$ & \\
\hline & General population & $N=323$ & $5.9 \%$ & $0.4 \%$ & $5.5 \%$ & $22.9 \%$ & $18.1 \%$ & eurogol \\
\hline & Test (p-value) & & $P<0.0001$ & $P<0.0001$ & $P<0.0001$ & $P<0.0001$ & $P<0.0001$ & \\
\hline \multirow[t]{4}{*}{ Italy } & RWC sample & $N=105$ & $35.2 \%$ & $22.9 \%$ & $56.2 \%$ & $78.1 \%$ & $61.9 \%$ & \\
\hline & General population & $N=4,709$ & $12.0 \%$ & $4.3 \%$ & $10.9 \%$ & $27.6 \%$ & $9.3 \%$ & Konig et al. \\
\hline & General pop (adjusted) & $N=4,709$ & $15.6 \%$ & $5.7 \%$ & $14.7 \%$ & $38.3 \%$ & $13.9 \%$ & \\
\hline & Test ( $p$-value) & & $P<0.0001$ & $P<0.0001$ & $P<0.0001$ & $P<0.0001$ & $P<0.0001$ & \\
\hline \multirow[t]{3}{*}{ Germany } & RWC sample & $N=106$ & $17.0 \%$ & $5.7 \%$ & $25.5 \%$ & $54.7 \%$ & $50.9 \%$ & \\
\hline & General population & $N=340$ & $7.4 \%$ & $1.1 \%$ & $6.7 \%$ & $27.4 \%$ & $19.6 \%$ & eurogol \\
\hline & Test (p-value) & & $P<0.0001$ & $P<0.0001$ & $P<0.0001$ & $P<0.0001$ & $P<0.0001$ & \\
\hline USA & RWC sample & $N=102$ & $29.4 \%$ & $20.6 \%$ & $33.3 \%$ & $57.8 \%$ & $55.9 \%$ & \\
\hline Total & RWC sample & $N=620$ & $17.0 \%$ & $5.7 \%$ & $25.5 \%$ & $54.7 \%$ & $50.9 \%$ & \\
\hline \multicolumn{9}{|c|}{ Spearman correlation coefficients with: } \\
\hline \multirow[t]{2}{*}{ Physical health - SF36 } & Correlation coeff. & & -0.41027 & -0.37495 & -0.41759 & -0.39627 & -0.21067 & \\
\hline & P-value & & $<.0001$ & $<.0001$ & $<.0001$ & $<.0001$ & $<.0001$ & \\
\hline \multirow[t]{2}{*}{ Mental health - SF36 } & Correlation coeff. & & -0.2122 & -0.18161 & -0.20143 & -0.22917 & -0.44891 & \\
\hline & P-value & & $<.0001$ & 0.0002 & $<.0001$ & $<.0001$ & $<.0001$ & \\
\hline
\end{tabular}

in the general population. Results were homogeneous across countries with T-scores varying from 34 to 37 for mental health scores and from 45 to 46 for the pain scores. The most significantly affected domains were those related to mental health, particularly the "emotional well-being" and "role limitation emotional" domains. The average mental component summary score was estimated at 34.72 (95\% CI: [33.74; 35.71]).

\section{Health state utility values during and outside infection periods}

Analyses comparing health state utilities during and outside infection periods were conducted for all countries except the UK (Figure 1 and Table 4). The average utility during the last infection, whenever it occurred (during the completion of questionnaire or before), was lower than the utility outside infection ( 0.51 vs. 0.70 ; Table 4 ). $90.8 \%$ of women had pain/discomfort problems during the last episode, vs. $60.8 \%$ outside infections, ( $<<0.0001$ ), on average across five countries. Differences were smaller on the anxiety/depression dimension, as many women reported suffering anxiety or depression between acute episodes.

The difference was smaller when separating women with or without infection at the time of completing the questionnaire: the utility score was estimated at 0.69 without infection vs. 0.64 with infection $(\mathrm{p}<0.001)$.

The regression model in Table 5 shows that respondents with a longer time since last symptoms had a higher utility on the day of questionnaire completion. For example, the difference in utility between women without symptoms for three months and those with symptoms in the past week was $0.1633(\mathrm{p}=0.0033)$, all other things equal. In addition, women undergoing long-term antifungal therapy had a significantly lower utility compared to those treated in the past or never treated. The effect of the time since the disease onset was tested but this variable was not included in the final model as it did not impact significantly the EQ-5D utility.

The health status of women with RVVC was not only lower than the general population during an acute episode, 


\begin{tabular}{|c|c|c|c|c|c|c|c|c|}
\hline & & UK & France & Spain & Italy & Germany & USA & Total \\
\hline \multicolumn{9}{|c|}{ All RVVC sample, during the day of completion of the questionnaire (a) } \\
\hline & $\mathrm{N}$ & 100 & 107 & 100 & 105 & 106 & 102 & 620 \\
\hline (UK TTO formula) & Mean (Sd) & $0.74(0.28)$ & $0.72(0.25)$ & $0.67(0.34)$ & $0.61(0.30)$ & $0.76(0.25)$ & $0.68(0.34)$ & $0.70(0.30)$ \\
\hline (country specific formula) & Mean (Sd) & $0.74(0.28)$ & $0.77(0.23)$ & $0.72(0.32)$ & - & $0.86(0.20)$ & $0.76(0.23)$ & - \\
\hline \multicolumn{9}{|c|}{ Women with infection, during the day of completion of the questionnaire } \\
\hline & $\mathrm{N}$ & & 5 & 4 & 7 & 7 & 7 & 30 \\
\hline (UK TTO formula) & Mean (Sd) & - & $0.62(0.41)$ & $0.48(0.30)$ & $0.73(0.10)$ & $0.79(0.34)$ & $0.53(0.33)$ & $0.64(0.31)$ \\
\hline (country specific formula) & Mean (Sd) & - & $0.78(0.22)$ & $0.73(0.33)$ & - & $0.87(0.20)$ & $0.77(0.23)$ & - \\
\hline \multicolumn{9}{|c|}{ Women Without infection, during the day of completion of the questionnaire } \\
\hline & N & & 102 & 96 & 98 & 99 & 95 & 490 \\
\hline (UK TTO formula) & & & $0.73(0.25)$ & $0.68(0.34)$ & $0.60(0.31)$ & $0.75(0.24)$ & $0.69(0.34)$ & $0.69(0.30)$ \\
\hline (country specific formula) & Mean (Sd) & & $0.78(0.22)$ & $0.73(0.33)$ & - & $0.87(0.20)$ & $0.77(0.23)$ & - \\
\hline \multicolumn{9}{|l|}{ General population (b) } \\
\hline & N & 3395 & 2892 & 5473 & 4709 & 3552 & 4000 & - \\
\hline & Mean (Sd) & $0.92(0.22)$ & $0.89(-)$ & $0.93(-)$ & $0.90(-)$ & $0.94(-)$ & $0.88(-)$ & $0.91(-)$ \\
\hline & Adjusted mean (Sd) & - & $0.86(-)$ & $0.89(-)$ & $0.87(-)$ & $0.92(-)$ & - & - \\
\hline & Source & $\begin{array}{r}\text { Dennis } \\
\text { et al. }\end{array}$ & König et al. & König et al. & König et al. & König et al. & Kind et al. & \\
\hline
\end{tabular}

Difference $(a-b)$

$$
\begin{array}{rrrrrrrrrr}
\text { (UK TTO formula) } & \text { Mean (Sd) } & -0.18(-) & -0.17(-) & -0.26(-) & -0.29(-) & -0.18(-) & -0.20(-) & -0.21(-) \\
& \text { Adjusted } & \text { mean (Sd) } & - & -0.14(-) & -0.22(-) & -0.26(-) & -0.16(-) & - & - \\
\text { (country specific formula) } & \text { Mean (Sd) } & -0.18(-) & -0.12(-) & -0.21(-) & - & -0.08(-) & -0.12(-) & - \\
& & - & -0.09(-) & -0.17(-) & - & -0.06(-) & - & - \\
& \begin{array}{r}
\text { Mean (Sd) } \\
\text { (adjusted) }
\end{array} & - & & & & & &
\end{array}
$$

During the last acute episode (at the completion of the questionnaire or before) (c)*

$\begin{array}{rrrrrrrrrr} & N & 100 & 107 & 100 & 105 & 106 & 102 & 520 \\ \text { (UK TTO formula) } & \text { Mean (Sd) } & 0.71(0.27) & 0.52(0.33) & 0.48(0.34) & 0.42(0.35) & 0.62(0.28) & 0.51(0.36) & 0.51(0.34) \\ \text { (country specific formula) } & \text { Mean (Sd) } & 0.71(0.27) & 0.59(0.31) & 0.54(0.35) & - & 0.76(0.24) & 0.64(0.24) & -\end{array}$

Symptom-free period (at the completion of the questionnaire or before) (d)*

$\begin{array}{rrrrrrrrrr} & N & 100 & 107 & 100 & 105 & 106 & 102 & 520 \\ \text { (UK TTO formula) } & \text { Mean (Sd) } & 0.86(0.24) & 0.72(0.26) & 0.68(0.34) & 0.62(0.31) & 0.77(0.24) & 0.69(0.33) & 0.70(0.30) \\ \text { Mean (Sd) } & 0.86(0.24) & 0.77(0.23) & 0.73(0.32) & - & 0.87(0.19) & 0.77(0.23) & -\end{array}$

\begin{tabular}{|c|c|c|c|c|c|c|c|c|}
\hline & N & 100 & 107 & 100 & 105 & 106 & 102 & 520 \\
\hline Utility score (UK TTO formula) & Mean (Sd) & $-0.15(0.23)$ & $\begin{array}{l}-0.20 \\
(0.29)\end{array}$ & $\begin{array}{l}-0.20 \\
(0.34)\end{array}$ & $\begin{array}{l}-0.20 \\
(0.30)\end{array}$ & $\begin{array}{l}-0.15 \\
(0.23)\end{array}$ & $\begin{array}{l}-0.18 \\
(0.27)\end{array}$ & $\begin{array}{l}-0.19 \\
(0.29)\end{array}$ \\
\hline $\begin{array}{r}\text { Utility score (country specific } \\
\text { formula) }\end{array}$ & Mean (Sd) & $-0.15(0.23)$ & $\begin{array}{l}-0.19 \\
(0.25)\end{array}$ & $\begin{array}{l}-0.19 \\
(0.32)\end{array}$ & - & $\begin{array}{l}-0.12 \\
(0.20)\end{array}$ & $\begin{array}{l}-0.12 \\
(0.18)\end{array}$ & \\
\hline
\end{tabular}

Difference $(c-d) *$

*Total do not include data from the UK, as questions about symptoms were formulated differently in the UK version.

but also outside infections. Large differences in the proportions of subjects reporting problems were found for the anxiety/depression dimension, between women with RVVC during infection-free periods (54\%) and women in general $(\leq 20 \%)$. The difference was largest in Italy, where $60 \%$ reported anxiety/depression problems outside episodes vs. 9.3\% in the general population (Figure 3).
Work productivity and activity impairment

Around 50\% of the RVVC sample claimed the disease impacted their daily normal activity (from $45 \%$ for UK to $60 \%$ for USA). In addition, working women with RVVC missed around six hours of work per episode of yeast infection (Table 6). Therefore, the individual number of missing hours (hours per episode * episodes per 


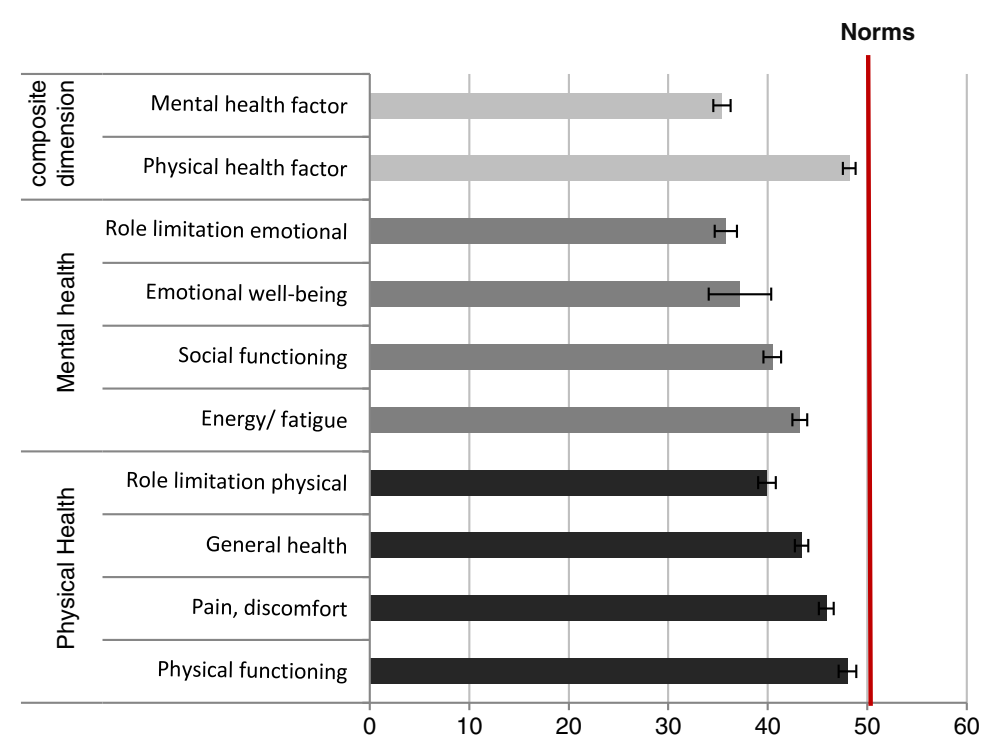

Figure 2 SF-36 T-scores for each dimension. All scales in the general population have the same average (50) and the same standard deviation (10).

year) was estimated at around 33 hours per year. The costs of lost productivity over 12 months were estimated at $€ 1,130 /$ per year for France, $€ 852 /$ per year for the UK (i.e. $€ 713$ ) and $€ 974 /$ per year for US (i.e. $\$ 1,261$ ).

\section{Correlations between instruments}

Correlations between SF-36 summary scales and EQ-5D ratings by dimension were weak to moderate. The SF-36 mental component summarily was moderately correlated with the EQ-5D anxiety/depression dimension (Spearman's correlation: 0.45$)$, and weakly correlated with other dimensions (0.18 to 0.23$)$. On the opposite, the SF-36 physical component summary was moderately correlated with mobility, self-care, usual activities and pain/discomfort (0.37 to 0.42 ), and weakly with anxiety/depression $(0.21)$.

The number of missing hours was strongly associated with the EQ-5D, specifically with ratings of problems with usual activities.

\section{Discussion}

The main objective of the survey was to elicit utility values for RVVC. The EQ-5D questionnaire, a widely used and recommended generic questionnaire for utility value elicitation, was used to quantify the impact of RVVC. This also allowed for comparison with general population norms and other diseases. The SF-36, another generic questionnaire, was used to describe in more detail the impact of RVVC in HRQoL.

The average health state utility for women with RVVC was estimated at 0.70 (based on the UK TTO formula), despite the use of long term antifungal therapy in $85 \%$ of participants. According to US and UK catalogues of utilities, this situates RVVC as worse than headache/migraine for example, and similar to asthma or COPD [34,35]. The difference $v s$. age-adjusted population norms was estimated at -0.21 globally, based on the UK tariff, and ranged from -0.12 for France to -0.21 for Spain, using

Table 5 Multivariate regression on the EQ-5D utility today (except UK)

\begin{tabular}{|c|c|c|c|c|}
\hline & Category & Reference & Estimates & P-value \\
\hline Age (years) & & & -0.0021 & 0.0779 \\
\hline \multirow[t]{3}{*}{ The last time you experienced symptoms } & 1 to 4 weeks ago & This week & 0.1161 & 0.0004 \\
\hline & 1 to 3 months & & 0.1507 & 0.0001 \\
\hline & More than 3 months & & 0.1633 & 0.0033 \\
\hline Number of yeast infection & 4-5 infections & 6 infections and more & 0.0507 & 0.0762 \\
\hline \multirow[t]{3}{*}{ When did you stop the antifungal long-term therapy? } & In the past 12 months & This treatment is still ongoing & 0.1566 & 0.0002 \\
\hline & More than 12 months ago & & 0.2249 & 0.0001 \\
\hline & Never treated & & 0.2081 & $<.0001$ \\
\hline
\end{tabular}




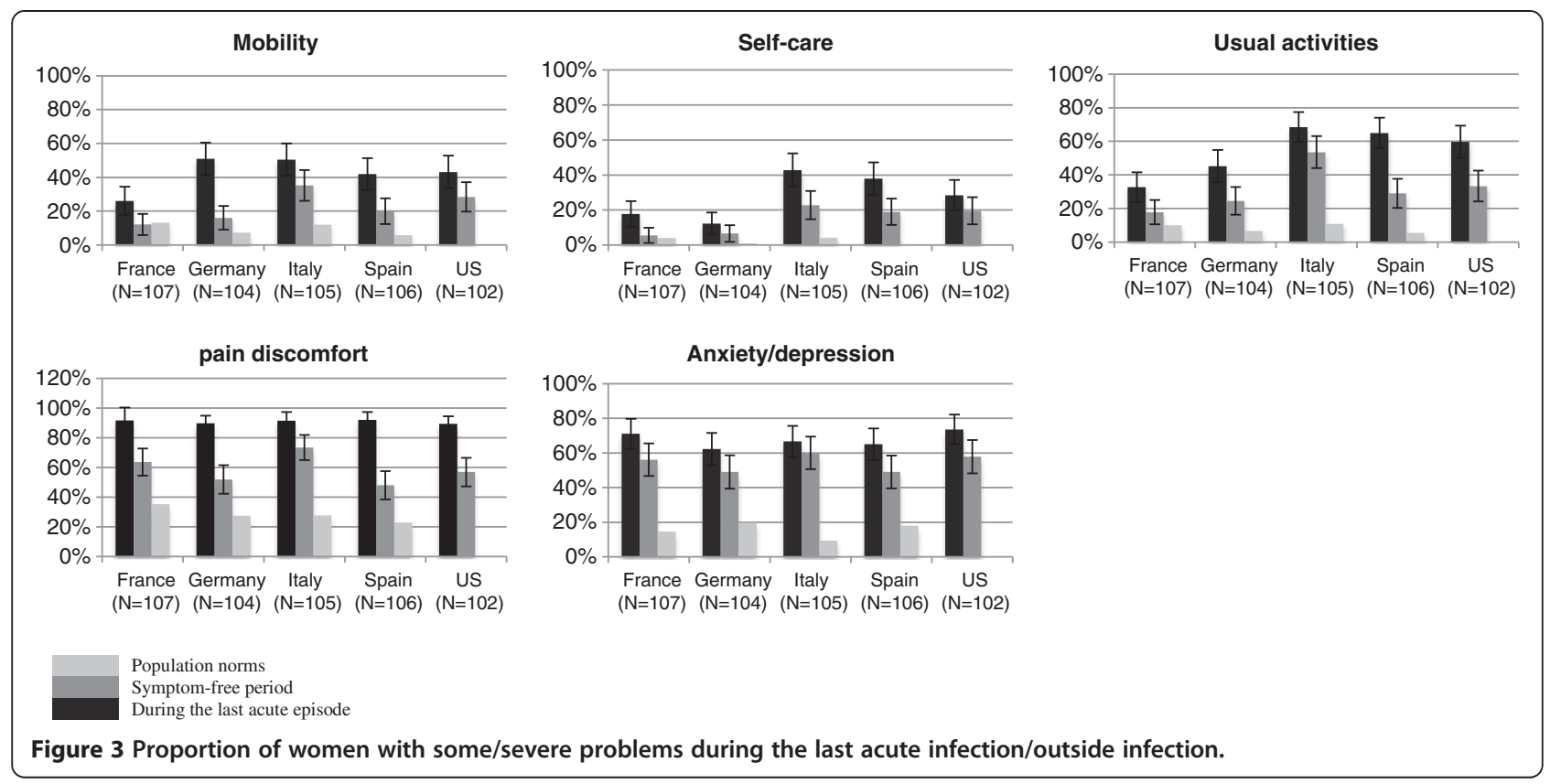

tariffs reflecting local preference weights. A minimal clinically important difference of 0.074 has been reported in the literature [36]. Thus, the utility decrement among women with RVVC was found to be clinically important for all countries.

SF-36 dimensions were all affected among women with RVVC in general. The greatest impact of the disease was found on the emotional domains compared to the general population, but significant differences were found for other domains as well. The summary scores of the SF-36 also suggested that mental health was strongly affected by RVVC (mean score: 34.72; 95\% CI: [33.74; 35.71] for all countries), which was consistent with the results from EQ-5D. This outcome was consistent with findings by Mendling et al., who also reported a stronger impact on mental health than on physical health using SF-36, albeit to a somewhat lesser extent [18].

Acute RVVC episodes impacted subjective health status negatively, but elicited health status was also affected outside RVVC episodes notably due to a large impact of the disease on anxiety or depression that lasts over time. Stress and a substantial psychological burden that is associated with the disease, up to depression, has been described previously and confirms the findings of the present study $[17,37,38]$. It is however not clear to what extent stress, anxiety and depression are causes or symptoms of RVVC, or both in an amplifying loop.

The impact of RVVC on subjective health status and HRQoL exists in spite of existing treatments, such as short- or long-term antifungal therapy. Many participants

Table 6 Productivity lost

\begin{tabular}{|c|c|c|c|c|c|c|c|}
\hline & UK & France & Spain & Italy & Germany & USA & Source \\
\hline & 100 & 107 & 100 & 105 & 106 & 102 & \\
\hline Number of employed women & $71(71.0 \%)$ & $83(77.5 \%)$ & $62(62.0 \%)$ & $60(57.1 \%)$ & $78(73.5 \%)$ & $69(67.7 \%)$ & \\
\hline Missing hours from work/RWC episode & $5.86(12.39)$ & $8.72(17.67)$ & $3.37(9.62)$ & $5.23(8.29)$ & $6.12(10.59)$ & $7.00(10.80)$ & \\
\hline Number of missing hours/year & 33.6 & 45.5 & 17.6 & 27.6 & 30.9 & 39.2 & \\
\hline Average annual hours actually worked per worker - 2011 (b) & 1625 & 1476 & 1690 & 1774 & 1413 & 1787 & OECD \\
\hline Average annual wages (National Currency Unit) - 2011 (c) & 31413 & 34284 & 27010 & 28109 & 33766 & 54450 & OECD \\
\hline Average daily wages (National Currency Unit) - 2011 (d) = (c)/(b) & 19.33 & 23.23 & 15.98 & 15.84 & 23.9 & 30.47 & \\
\hline Average daily wages. in $€$ & $19.33^{*}$ & 23.23 & 15.98 & 15.84 & 23.9 & $23.53^{* *}$ & \\
\hline $\begin{array}{l}\text { Monetary equivalence of the annual productivity loss }(€) \\
\text { (mean.sd) }\end{array}$ & $\begin{array}{r}851.6 \\
(1580)\end{array}$ & $\begin{array}{l}1129.9 \\
(2316)\end{array}$ & $\begin{array}{r}265.7 \\
(677)\end{array}$ & $\begin{array}{r}455.1 \\
(679)\end{array}$ & $\begin{array}{r}785.0 \\
(1384)\end{array}$ & $\begin{array}{r}973.9 \\
(1613)\end{array}$ & \\
\hline
\end{tabular}

*Conversion rate: 31/12/2011: 1.193.

${ }^{* *}$ Conversion rate: 31/12/2011: 0.7722 . 
had previously received long-term antifungal therapy. Women who were receiving a long-term antifungal therapy at the time of the study had worse subjective health status compared to others; this was likely related to the fact that those who sought treatment were the women in whom subjective health status was most affected.

The impact on productivity, estimated at 33 work hours lost per year on average, was high. Associated costs ranged from $€ 266 /$ year for Spain to $€ 1,130 /$ year for France. These values were higher than expected, but they seemed credible as there was good internal consistency between the rating of usual activities and the number of missed work hours per episode from WPAI.

The survey was conducted in a large sample of women $(n=620)$, covering six countries. Despite variability in health state utility values and HRQoL scores between countries, the key findings were consistent between countries. Differences in utility values and HRQoL scores between RVVC and the general population were always significant and clinically important. In addition, the correlations between EQ-5D and SF-36 were in line with expectations: the EQ-5D physical dimensions were mostly correlated to SF-36 physical domains and the EQ-5D anxiety/disorder rating was mostly correlated to SF-36 mental domains. The extent of correlation between EQ-5D and SF-36 was consistent with previous studies, also reporting low to moderate correlations between the two instruments (for example in low back pain [39]).

A limitation of this study was that data on co-morbidities was not available. It is possible that the difference in utility between women with RVVC and the general population was partially attributable to co-morbidities with higher occurrence in RVVC patients than in the general population [1,2]. In some rare cases, yeast infection may be an early sign of diabetes [40]. This could explain why there were more women with RVVC reporting problems on dimensions such as mobility, outside infection periods. However, regression analysis demonstrated that utility worsens with increasing disease severity, and therefore, that the estimated reduction in utility was at least partially attributable to RVVC itself. In addition, vestibular vulvodynia, is often present in RVVC patients. The causal relationship between RVVC and vestibular vulvodynia is not clear. Vestibular vulvodynia could be a symptom of RVVC or a comorbidity triggered by RVVC as suggested by a recent report [41], although this pain syndrome may also have other origins.

The study was also limited by the fact that online selfreported answers could not be verified, in particular the diagnosis. However, women were not asked to state directly, whether they had RVVC or not. The screening section was designed in a way that respondents did not know that the topic was RVVC until the completion of all five screening questions, where they were asked about a physician-diagnosed episode of VVC (or suggested synonyms) and the number of such episodes over the past 12 months. Although women could receive a small financial incentive to participate, (from $€ 0.5$ to $€ 5$ ), this incentive was sufficiently small not to attract "false respondents", who would participate only in order to receive the financial incentive.

The proportion of women with symptoms on the day of the questionnaire (5.8\%) was lower than expected (according to average number of days and average duration of an episode). Potential reasons for this relatively low proportion may be that symptoms are not continuous during acute episodes, or that women with RVVC are less likely to participate in online surveys during acute episodes. However, the sum of the number of women with an acute episode at the time of questionnaire completion or in the past week was consistent with the number of episodes per year and the duration of an acute episode.

A minor limitation for the UK sample was that the question about the presence of symptoms on the day of completing the questionnaire appeared to be misunderstood in the soft launch and therefore had to be rephrased before launching the surveys in other countries. Utilities for acute episodes and periods in between episodes could thus not be separated for the UK. However all other parts of the questionnaire were identical, and global RVVC utilities on the day of questionnaire completion are comparable between the UK and other countries.

When testing for the significance between utilities among women with RVVC and the general population, the standard error around utility norms was ignored. Standard errors around the utility norms were not available for some countries, but these were known to be small compared to estimated differences between women with RVVC and women in general for the UK and the US. In the UK, the standard error around the utility norm for women were $0.005(\mathrm{SD}=0.22 ; \mathrm{N}=1,925)$. In the $\mathrm{US}$, standard errors of scores in each age or gender category were around 0.02 .

Another limitation was the calculation of the utility during acute episodes by pooling women having an acute episode at completion of the questionnaire with women recalling the last acute episode (having occurred on average 2.2 months ago, but in any case within the past 12 months). It was uncertain how well women could recall the quality of life during the last episode. We noted, however, that the reported difference in EQ5D utility during and between episodes was very similar for patients who answered the questionnaire during an acute episode and those who answered in the interval between episodes ( 0.20 and 0.19 , respectively).

We used modified versions of the WPAI questionnaire. Questions were reworded replacing "During the past seven days ..." by "Thinking back to your most recent 
yeast infection..." and the "...your health problems..." by "...your last infection...". The WPAI questionnaire, while being validated in English and Spanish, has not been validated in German, French or Italian placing a potential limitation on the accuracy of the data gathered from respondents from these countries. However, all translations were carefully reviewed by native speakers and clinicians.

\section{Conclusions}

This survey showed that subjective health status and HRQoL are substantially diminished during acute episodes, but also outside these episodes in women with RVVC, including some women who have received longterm antifungal therapy as recommended by guidelines. It appears that many women with RVVC suffered some discomfort, and most importantly anxiety between acute episodes. The survey also revealed that the disease has a strong impact on patient's usual daily activities and work. RVVC was found to be associated with significant productivity costs. These findings highlight the need for more effective ways to manage RVVC.

\section{Endnotes}

${ }^{a}$ The proportion of women reporting having symptoms while answering the questionnaire (80\%) was much higher than expected in the UK. The question was probably misunderstood. Based on the UK results, the questions on symptoms were revised before the launch in other countries.

\section{Competing interests}

The authors declare that they have no competing interests.

\section{Authors' contributions}

SA participated in the conception of the study and the questionnaire, supervised the analysis, contributed in the interpretation of data and revised the manuscript critically. FG participated in the design of the questionnaire, supervised the analysis, interpreted the data and drafted the manuscript. AK performed the data management and the statistical analysis and contributed in the interpretation of the data. JW participated in the conception of the study, revised the manuscript critically for important intellectual content and gave final approval of the version to be published. JPD participated in the conception of the study, revised the manuscript critically for important intellectual content and gave final approval of the version to be published. JS contributed in the interpretation of data and revised the manuscript critically for important intellectual content. MT revised the manuscript critically for important intellectual content and gave final approval of the version to be published. All authors read and approved the final manuscript.

\section{Acknowledgements}

We would like to thank Prof. Betsy Foxman, Department of Epidemiology, University of Michigan, Ann Arbor, USA, for valuable input on the conception of the study and critical review of the manuscript.

\section{Funding}

This study was supported by an unconditional grant from Pevion Biotech AG, Switzerland.

This study was funded by Pevion Biotech AG.

\section{Author details}

'Université Lyon I, decision sciences and health policies, Lyon, France.

${ }^{2}$ Université EPHE, Paris, France. ${ }^{3}$ Pevion Biotech AG, Ittigen/Bern, Switzerland.
${ }^{4}$ Creativ-Ceutical SA, Paris, France. ${ }^{5}$ HMAccess, Health and Market Access Strategies S.A.S, Menthon, France. ${ }^{6}$ Division of Infectious Diseases, Department of Internal Medicine, Wayne State University, Detroit, USA.

Received: 15 January 2013 Accepted: 16 September 2013

Published: 11 October 2013

\section{References}

1. Mardh PA, Rodrigues AG, Genc M, Novikova N, Martinez-de-Oliveira J, Guaschino S: Facts and myths on recurrent vulvovaginal candidosis-a review on epidemiology, clinical manifestations, diagnosis, pathogenesis and therapy. Int J STD AIDS 2002, 13(8):522-539.

2. Donders GG, Bellen G, Mendling W: Management of recurrent vulvovaginal candidosis as a chronic illness. Gynecol Obstet Invest 2010, 70(4):306-321.

3. Foxman B, Muraglia R, Dietz JP, Sobel JD, Wagner J: Prevalence of recurrent vulvovaginal candidiasis in 5 European countries and the US: results from an internet panel survey. J Low Genit Tract Dis 2013, 17(3). nn [epub ahead of print].

4. Foxman B, Barlow R, D'Arcy H, Gillespie B, Sobel JD: Candida vaginitis: selfreported incidence and associated costs. Sex Transm Dis 2000, 27(4):230-235.

5. Corsello S, Spinillo A, Osnengo G, Penna C, Guaschino S, Beltrame A, Blasi N, Festa A: An epidemiological survey of vulvovaginal candidiasis in Italy. Eur J Obstet Gynecol Reprod Biol 2003, 110(1):66-72.

6. Richter SS, Galask RP, Messer SA, Hollis RJ, Diekema DJ, Pfaller MA: Antifungal susceptibilities of Candida species causing vulvovaginitis and epidemiology of recurrent cases. J Clin Microbiol 2005, 43(5):2155-2162.

7. Engberts MK, Korporaal H, Vinkers M, van Belkum A, van Binsbergen J, Lagro-Janssen T, Helmerhorst T, van der Meijden W: Vulvovaginal candidiasis: diagnostic and therapeutic approaches used by Dutch general practitioners. Eur J Gen Pract 2008, 14(1):30-33.

8. Johnson SR, Griffiths H, Humberstone FJ: Attitudes and experience of women to common vaginal infections. J Low Genit Tract Dis 2010, 14(4):287-294.

9. Pappas PG, Kauffman CA, Andes D, Benjamin DK Jr, Calandra TF, Edwards JE Jr, Filler SG, Fisher JF, Kullberg BJ, Ostrosky-Zeichner L, Reboli AC, Rex JH, Walsh TJ, Sobel JD: Clinical practice guidelines for the management of candidiasis: 2009 update by the infectious diseases society of America. Clin Infect Dis 2009, 48(5):503-535.

10. Mendling W, Seebacher C, Working Group for Infections and Infectimmunology of the German Society for Gynecology and Obstetrics, German Speaking Mycological Society, German Dermatological Society: Guideline vulvovaginal candidosis: guideline of the German dermatological society, the German speaking mycological society and the working group for infections and infectimmunology of the German society for gynecology and obstetrics. Mycoses 2003, 46(9-10):365-369.

11. Sobel JD, Wiesenfeld HC, Martens M, Danna P, Hooton TM, Rompalo A, Sperling M, Livengood C 3rd, Horowitz B, Von Thron J, Edwards L, Panzer H, Chu TC: Maintenance fluconazole therapy for recurrent vulvovaginal candidiasis. N Engl J Med 2004, 351(9):876-883.

12. Bolouri F, Moghadami Tabrizi N, Niroomand N, Azmoodeh A, Emami S, Falahati M: Effectiveness of fluconazole for suppressive maintenance therapy in patients with RVVC: a randomized placebo-controlled study. Iranian Journal of Pharmaceutical Research 2009, 8(4):307-313.

13. Donders G, Bellen G, Byttebier G, Verguts L, Hinoul P, Walckiers R, Stalpaert $M$, Vereecken A, Van Eldere J: Individualized decreasing-dose maintenance fluconazole regimen for recurrent vulvovaginal candidiasis (ReCiDiF trial. Am J Obstet Gynecol 2008, 199:613e9.

14. Watson C, Pirotta M: Recurrent vulvovaginal candidiasis - current management. Aust Fam Physician 2011, 40(3):149-151.

15. Watson CJ, Pirotta M, Myers SP: Use of complementary and alternative medicine in recurrent vulvovaginal candidiasis-results of a practitioner survey. Complement Ther Med 2012, 20(4):218-221.

16. Nyirjesy P, Robinson J, Mathew L, Lev-Sagie A, Reyes I, Culhane JF: Alternative therapies in women with chronic vaginitis. Obstet Gynecol 2011, 117(4):856-861.

17. Nyirjesy P, Peyton C, Weitz MV, Mathew L, Culhane JF: Causes of chronic vaginitis: analysis of a prospective database of affected women. Obstet Gynecol 2006, 108(5):1185-1191.

18. Mendling W, Birkner V: Vaccination with inactivated Lactobacilli or heliotherapy can improve the quality-of-life of women with chronic 
recurrent vulvovaginal candidosis - a prospective randomized study. Geburtsh Frauenheilk 2011, 71(9):767-772 [Article in German]

19. Research Now. [www.researchnow.com]

20. Rabin R, de CF: EQ-5D: a measure of health status from the EuroQol Group. Ann Med 2001, 33(5):337-343.

21. Brazier J, Roberts J, Deverill M: The estimation of a preference-based measure of health from the SF-36. J Health Econ 2002, 21(2):271-292.

22. Garratt A, Schmidt L, Mackintosh A, Fitzpatrick R: Quality of life measurement: bibliographic study of patient assessed health outcome measures. BMJ 2002, 324(7351):1417.

23. National Institute for Clinical Excellence: Guide to the Methods of Technology Appraisal. London: National Institute for Clinical Excellence; 2004 [http://www.nice.org.uk/niceMedia/pdf/TAP_Methods.pdf]

24. EuroQol: A new facility for the measurement of health-related quality of life. The EuroQol Group. Health Policy 1990, 16(3):199-208.

25. Ware JE, Kosinski M: SF-36 physical and mental health summary scales: a manual for users of version 1. 2nd edition. Lincoln, Rl: Quality Metric Inc.; 2001.

26. Reilly MC, Zbrozek AS, Dukes EM: The validity and reproducibility of a work productivity and activity impairment instrument. Pharmacoeconomics 1993, 4(5):353-365.

27. OECD. [http://stats.oecd.org]

28. Eurogol. [http://www.eurogol.org]

29. König HH, Bernert S, Angermeyer MC, Matschinger H, Martinez M, Vilagut G: Comparison of population health status in six european countries: results of a representative survey using the EQ-5D questionnaire. Med Care 2009, 47(2):255-261.

30. Szende A, Williams A: Measuring Self-Reported Population Health - An International Perspective based on EQ-5D. ; 2012 [http://www.eurogol.org]

31. Fryback DG, Dunham NC, Palta M, Hanmer J, Buechner J, Cherepanov D, et al: US norms for six generic health-related quality-of-life indexes from the National Health Measurement study. Med Care 2007, 45(12):1162-1170.

32. Erens B: Health-related quality of life: general population survey. London: Social and Community Planning Research; 1994. Technical report.

33. Kind P, Hardman G, Macran S: UK population norms for EQ-5D, Volume No 172chedp, Working Papers. University of York: Centre for Health Economics. http://EconPapers.repec.org/RePEc:chy:respap:172chedp.

34. Sullivan PW, Slejko JF, Sculpher MJ, Ghushchyan V: Catalogue of EQ-5D scores for the United Kingdom. Med Decis Making 2011, 31(6):800-804.

35. Sullivan PW, Lawrence WF, Ghushchyan V: A national catalog of preference-based scores for chronic conditions in the United States. Med Care 2005, 43(7):736-749.

36. Walters SJ, Brazier JE: Comparison of the minimally important difference for two health state utility measures: EQ-5D and SF-6D. Qual Life Res 2005, 14(6):1523-1532.

37. Ehrström SM, Kornfeld D, Thuresson J, Rylander E: Signs of chronic stress in women with recurrent candida vulvovaginitis. Am J Obstet Gynecol 2005, 193(4):1376-1381.

38. Meyer $\mathrm{H}$, Goettlicher $\mathrm{S}$, Mendling W: Stress as a cause of chronic recurrent vulvovaginal candidosis and the effectiveness of the conventional antimycotic therapy. Mycoses 2006, 49(3):202-209.

39. Eker L, Tüzün EH, Daskapan A, Bastug ZÖ, Yakut Y: Relationship between EQ-5D and SF-36 instruments in patients with low back pain. Fizyoter Rehabil 2007, 18(1):03-10.

40. De Leon EM, Jacober SJ, Sobel JD, Foxman B: Prevalence and risk factors for vaginal Candida colonization in women with type 1 and type 2 diabetes. BMC Infect Dis 2002, 2:1

41. Farmer MA, Taylor AM, Bailey AL, Tuttle AH, Maclntyre LC, Milagrosa ZE, Crissman HP, Bennett GJ, Ribeiro-da-Silva A, Binik YM, Mogil JS: Repeated vulvovaginal fungal infections cause persistent pain in a mouse model of vulvodynia. Sci Transl Med 2011, 3(101):101ra91.

doi:10.1186/1477-7525-11-169

Cite this article as: Aballéa et al:: Subjective health status and healthrelated quality of life among women with Recurrent Vulvovaginal Candidosis (RVVC) in Europe and the USA. Health and Quality of Life Outcomes 2013 11:169.

\section{Submit your next manuscript to BioMed Central and take full advantage of:}

- Convenient online submission

- Thorough peer review

- No space constraints or color figure charges

- Immediate publication on acceptance

- Inclusion in PubMed, CAS, Scopus and Google Scholar

- Research which is freely available for redistribution

Submit your manuscript at www.biomedcentral.com/submit
C Biomed Central 